\title{
Efeito da energia de soldagem e da espessura do aço inoxidável duplex sobre as transformações na zona afetada pelo calor
}

\author{
Effects of the welding energy and thickness of the duplex stainless steel \\ on the heat affected zone transformations
}

\author{
Bruno Henrique Dias Guimarães ${ }^{1}$, Carlos Roberto Xavier², Célio de Jesus Marcelo \\ José Adilson de Castro ${ }^{1}$, Marcos Flávio de Campos ${ }^{1}$
}

\begin{abstract}
Resumo
Os aços inoxidáveis duplex (AIDs) são ligas Fe-Cr-Ni-Mo, com excelentes propriedades mecânicas e de resistência à corrosão devido, basicamente, a uma microestrutura balanceada com igual proporção entre as fases ferrita e austenita. Devido às suas propriedades, os AIDs se tornam bastante atrativos para utilização, entre outras, nas indústrias química, petroquímica, de papel, alimentícia e farmacêutica. Entretanto, durante as etapas de processamento e fabricação, estes aços podem ficar expostos a determinadas faixas de temperaturas ou ciclos térmicos, como aqueles que ocorrem durante a soldagem, podendo ocorrer a precipitação de fases frágeis, notadamente da fase sigma, e um desbalanceamento na proporção entre ferrita e austenita que podem comprometer seriamente as suas propriedades. Este trabalho teve como objetivo avaliar a influência da energia de soldagem e da espessura do metal base sobre a microestrutura da zona afetada pelo calor (ZAC) do aço inoxidável duplex SAF 2205 quando submetido à deposição de um cordão de solda através do processo Gas Metal Arc Welding (GMAW). Análise microestrutural utilizando microscopia óptica, microscopia eletrônica de varredura (MEV) e difração de raios-X foi efetuada na ZAC dos aços soldados e não foi constatada a presença de fase sigma na faixa de energia de soldagem investigada neste trabalho.
\end{abstract}

Palavras-chave: Aço Inoxidável Duplex; Soldagem; Caracterização Microestrutural.

\begin{abstract}
Duplex stainless steel (DSS) are Fe-Cr-Ni-Mo alloys, which presents excellent mechanical properties and corrosion resistance. This is due, basically, to the balanced proportions between ferrite and austenite. These characteristics make DSS attractive materials for application in the chemical, petrochemical, cellulose, food and pharmaceutical industries. However, during manufacturing procedures, DSS can be submitted to determined temperatures range or thermal cycles as those occurring at the welding. This heating favors the precipitation of brittle phases, as sigma phase, thus impairing the ideal balance between the ferrite and austenite phases which can seriously affect their properties. This work aimed to evaluate the welding energy effect and the base metal thickness on the sigma phase precipitation in 2205 DSS when submitted to the deposition of a single weld bead by the Gas Metal Arc Welding (GMAW) process. Optical microscopy, scanning electronic microscopy (SEM) and X-ray diffraction were used for microestrutural characterization of the welded samples of this steel and no evidence of sigma phase was observed at the heat affected zone (HAZ) at the range of evaluated welding energy.
\end{abstract}

Keywords: Duplex stainless steel; Welding; Microestrutural characterization. 


\section{Introdução}

Os aços inoxidáveis duplex (AID) são materiais baseados no sistema Fe-Cr-Ni. Sua composição química e o processamento termomecânico conferem-lhes uma microestrutura bifásica com proporções aproximadamente iguais de ferrita e austenita ${ }^{(1)}$. A solidificação de um AID é completamente ferrítica. Na medida em que avança o resfriamento, parte desta ferrita se transforma, no estado sólido, em austenita. Os AIDs contém, tipicamente, cerca de 20 a $30 \%$ de cromo, 5,0 a $10 \%$ de níquel e 1,5 a $5,0 \%$ de molibdênio, com teores muito baixo de carbono (geralmente menor que $0,03 \%$ ) e podem ter adições de nitrogênio, cobre e tungstênio ${ }^{(2)}$. Eles apresentam várias vantagens sobre os aços inoxidáveis austeníticos e ferríticos. A resistência mecânica é aproximadamente o dobro da dos aços austeníticos, combinada com uma boa tenacidade.

Grande parte das aplicações atuais dos AIDs envolve algum processo de soldagem, e se não forem tomados os devidos cuidados na soldagem desses materiais, as vantagens dos AIDs sobre os aços inoxidáveis convencionais podem ser perdidas.

Durante a soldagem dos AID, além de procurar garantir o balanço final entre as fases ferrita e austenita, é igualmente importante se evitar a presença de fases frágeis, notadamente da fase sigma, devido à sua influência nas propriedades mecânicas e de resistência à corrosão. Ela apresenta estrutura tetragonal e é basicamente composta por $\mathrm{Fe}, \mathrm{Cr}$ e Mo. É caracterizada por elevados níveis de dureza (900 a $1000 \mathrm{HV})$ e fragilidade a temperatura ambiente ${ }^{(4)}$.

A Zona Afetada pelo Calor de Temperatura Elevada (ZACTE) é a região da Zona Afetada pelo Calor (ZAC) que é delimitada pelas temperaturas solvus da ferrita e a temperatura solidus da liga, onde o aço inoxidável duplex está completamente ferritizado ${ }^{(1)}$.

As energias de soldagem utilizadas na soldagem dos AID devem ser altas o suficiente para promover a formação de austenita e baixas o suficiente para se prevenir a precipitação de fases deletérias ${ }^{(4)}$. Na prática, um tempo de resfriamento entre $4 \mathrm{~s}$ e $15 \mathrm{~s}$ na faixa entre $1.200^{\circ} \mathrm{C}$ e $800^{\circ} \mathrm{C}(\Delta \mathrm{t} 12-8)$ têm sido recomendados. Este tempo de resfriamento é normalmente obtido, dependendo da espessura do metal de base e geometria da junta, com energia de soldagem entre 0,5 e $2,0 \mathrm{~kJ} / \mathrm{mm}^{(5)}$.

O presente trabalho teve como objetivo avaliar a influência da energia de soldagem e da espessura do metal base sobre a transformação microestrutural ocorrida na ZAC do aço inoxidável duplex SAF 2205 ao ser submetido à deposição de um cordão de solda através do processo Gas Metal Arc Welding (GMAW). A região da ZAC escolhida para estudo foi a zona afetada pelo calor de temperatura elevada (ZACTE).

\section{Materiais e Métodos}

Os materiais para estudo foram chapas laminadas de aço inoxidável duplex SAF 2205, sua composição química é dada na Tabela 1.

As soldagens foram realizadas através do processo GMAW (MIG/MAG), em simples deposição sem utilização de chanfro, sobre chapas laminadas de aço inoxidável duplex SAF 2205 com espessura de 10 e $20 \mathrm{~mm}$. Como metal de adição foi empregado o eletrodo da marca ESAB. A composição química do metal de adição utilizado é dada na Tabela 2. A composição do gás utilizado é dada na Tabela 3. Para todos os casos foi utilizada a vazão de 15 l/min. Os parâmetros de soldagem utilizados são dados na Tabela 4.

Preparação das amostras para metalografia

No lixamento foram utilizadas lixas de Carbeto de Silício (SiC) com resfriamento e lubrificação por água, com granulometrias: 220, 320, 400, 600, 800, 1000, 1200 e 1500. Em seguida foi realizado o polimento das amostras com pasta de diamante na sequência: 6,3,1 e 1/4 mm de tamanho médio de partícula. Para realizar o polimento das amostras foram utilizadas as politrizes rotativas, da marca Struers.

Tabela 1. Composição química do AID SAF 2205 (\% em peso).

\begin{tabular}{|c|c|c|c|c|c|c|c|c|c|}
\hline $\mathbf{C}$ & $\mathbf{M n}$ & $\mathbf{P}$ & $\mathbf{S}$ & $\mathbf{S i}$ & $\mathbf{C u}$ & $\mathbf{C r}$ & $\mathbf{M o}$ & $\mathbf{N i}$ & $\mathbf{N}$ \\
\hline 0,023 & 1,85 & 0,32 & 0,001 & 0,32 & 0,03 & 22,50 & 2,90 & 5,3 & 0,166 \\
\hline
\end{tabular}

Tabela 2. Composição química do metal de adição (\% em peso).

\begin{tabular}{|c|c|c|c|c|c|c|c|c|c|c|c|}
\hline $\mathbf{C}$ & $\mathbf{M n}$ & $\mathbf{P}$ & $\mathbf{S}$ & $\mathbf{S i}$ & $\mathbf{C u}$ & $\mathbf{C r}$ & $\mathbf{M} \mathbf{N}$ & $\mathbf{N i}$ \\
\hline 0,01 & 1,60 & 0,01 & 0,01 & 0,60 & 0,03 & 23,00 & 3,03 & 9,00 & 0,10 \\
\hline
\end{tabular}


Tabela 3. Composição do gás utilizado*.

\begin{tabular}{|c|c|}
\hline Gás & Composição (\%) \\
\hline 1 & $95 \% \mathrm{Ar}-3 \% \mathrm{CO}_{2}-2 \% \mathrm{~N}_{2}$ \\
\hline *Composição química e aplicação patenteadas pela White Martins/Praxair
\end{tabular}

Tabela 4. Parâmetros de soldagem utilizados.

\begin{tabular}{c|c|c|c}
$\mathbf{C P}$ & Gás & $\begin{array}{c}\text { Espessura } \\
(\mathbf{m m})\end{array}$ & $\begin{array}{c}\text { Energia } \\
\mathbf{( k J / m m})\end{array}$ \\
\hline 1 & $\mathrm{Ar}-\mathrm{CO}_{2}-\mathrm{N}_{2}$ & 10 & 0,66 \\
\hline 2 & $\mathrm{Ar}-\mathrm{CO}_{2}-\mathrm{N}_{2}$ & 10 & 2,57 \\
\hline 3 & $\mathrm{Ar}-\mathrm{CO}_{2}-\mathrm{N}_{2}$ & 20 & 0,66 \\
\hline 4 & $\mathrm{Ar}-\mathrm{CO}_{2}-\mathrm{N}_{2}$ & 20 & 2,57 \\
\hline
\end{tabular}

Com as amostras devidamente polidas realizou-se o ataque químico com a solução BEHARA II. Os componentes desta solução são: água $\left(\mathrm{H}_{2} \mathrm{O}\right)$, ácido clorídrico $(\mathrm{HCl})$ e metabissulfito de potásio $\left(\mathrm{K}_{2} \mathrm{~S}_{2} \mathrm{O}_{5}\right)$. Inicialmente foi preparada a solução estoque, constituída de uma mistura de $1000 \mathrm{ml}$ de água com $200 \mathrm{ml}$ de ácido clorídrico. Esta solução pode ser armazenada por até dois anos, já o metabissulfito de potássio deve ser adicionado somente no momento do ataque, pois seu período de atuação na solução é bastante curto. Para cada $100 \mathrm{ml}$ de solução estoque foram adicionados $0,3 \mathrm{~g}$ de metabissulfito de potássio. As amostras foram atacadas até que suas superfícies adquirissem uma coloração azul escuro. Feito isso, as amostras foram tiradas da solução e imediatamente lavadas com álcool etílico absoluto e secadas em ar quente com o auxílio de um secador.

Difração de raios-X

As amostras soldadas foram submetidas ao ensaio de difração de raios-X com o intuito de verificar se houve precipitação da fase sigma. Os corpos de prova para a difração de raios- $X$ foram preparados com a mesma seqüência de lixas usadas na preparação para análise metalográfica, porém sem polimento e sem ataque. O equipamento utilizado foi o Difratômetro Shimadzu XRD-6000 análise Rietveld em software TOPAS ACADEMIC 4.1

\section{Microscopia Eletrônica de Varredura (MEV)}

As amostras soldadas foram analisadas, também, através de microscopia eletrônica de varredura (MEV). O equipamento utilizado foi o Microscópio Eletrônico de Varredura Zeiss modelo EVO MA-10A, operando a uma tensão de 25 kV. Foram utilizadas imagens geradas por elétrons secundários e elétrons retroespalhados.

\section{Resultados e Discussões}

Inicialmente foi feita a preparação e análise do material como recebido. Na Fig. 1 é mostrada a microestrutura do material como recebido consistindo em grãos lamelares de ferrita e austenita. Na Tabela 5 têm-se o resultado da quantificação das fases.

Nas Figs. 2 e 3 são mostradas as micrografias da Zona Afetada pelo Calor de Temperatura Elevada (ZACTE) das amostras soldadas. Verifica-se, pela análise metalográfica, que não houve indício de precipitação da fase sigma com as energias utilizadas.

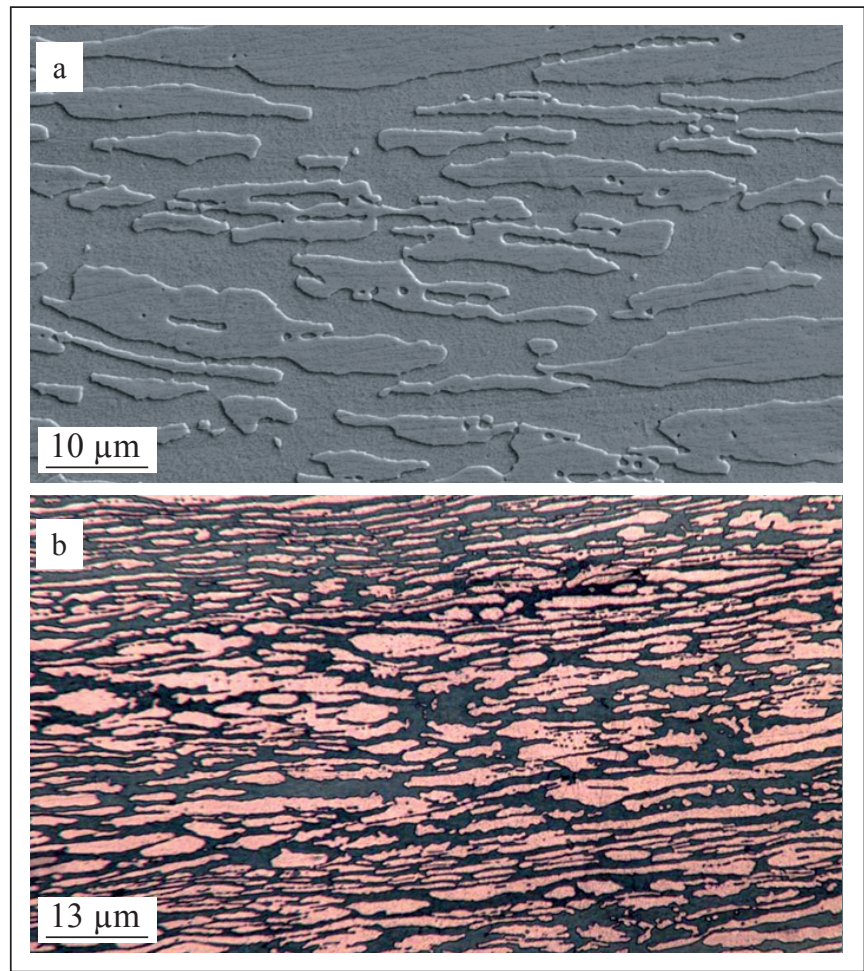

Figura 1. Microestrutura do material como recebido: (a) MEV e (b) Microscopia Ótica - fase clara austenita e fase escura ferrita. Ataque BEHARA II.

Tabela 5. Quantificação do metal base como recebido.

\begin{tabular}{|c|c|}
\hline $\begin{array}{c}\text { Fração de ferrita } \\
(\%)\end{array}$ & $\begin{array}{c}\text { Fração de austenita } \\
(\%)\end{array}$ \\
\hline 46 & 53 \\
\hline
\end{tabular}

De acordo com as Figs. 2 e 3 e a Tabela 6 pode-se notar que a quantidade de ferrita na ZACTE aumenta com o aumento 
da energia de soldagem. Quanto maior a energia de soldagem, maior o tempo que a região da ZACTE fica acima da temperatura solvus da ferrita. De acordo com $\mathrm{VAROL}^{(6)}$, o crescimento de grão que acontece quando a ZACTE é submetida a tempos longos acima da temperatura solvus da ferrita, pode levar à diminuição da austenita formada durante o resfriamento. Isto, porque para grandes tamanhos de grão ferrítico, será menor a área de contornos de grão para a nucleação da austenita, para um dado volume de material. Durante o processo de soldagem em um AID, no decorrer do aquecimento e do resfriamento, ocorrem mudanças microestruturais do material. Estas mudanças devem ser controladas de modo que as propriedades da junta soldada sejam as melhores possíveis.

Segundo Modenesi $i^{(7)}$, para uma mesma condição de soldagem, uma junta de maior espessura permite um escoamento
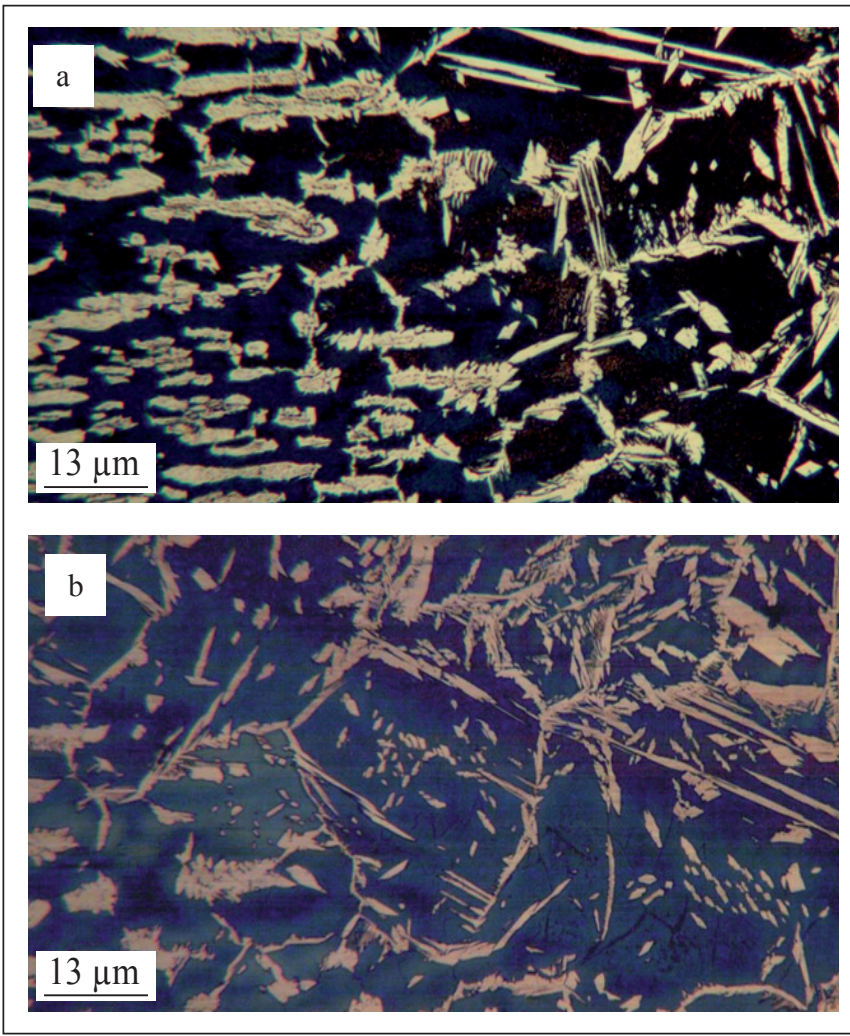

Figura 2. Micrografias da ZACTE das amostras soldadas com energias de 0,66 kJ/mm. Espessuras: (a) $10 \mathrm{~mm}$, (b) $20 \mathrm{~mm}$. Fase clara austenita e fase escura ferrita. Ataque BEHARA II. mais fácil do calor por condução. Assim, quanto mais espessa a junta, mais rapidamente esta tenderá a se resfriar durante a soldagem. A transformação no estado sólido, para o AID, de ferrita em austenita acontece por difusão. Com maiores velocidades de resfriamento essas transformações podem ser comprometidas e, assim, diminuir a quantidade de austenita do material. Entretanto, nas condições estudadas neste trabalho, não se observou um significativo aumento da fração volumétrica de ferrita presente na ZACTE ao se comparar duas diferentes espessuras de metal base utilizando-se uma mesma energia de soldagem (Tabela 6).

A difração de raios-X foi feita na ZACTE de todas as amostras soldadas. De acordo com as difrações de raios-X, não foi constatada a presença de fase sigma na faixa de energia de soldagem investigada neste trabalho. Todas as amostras
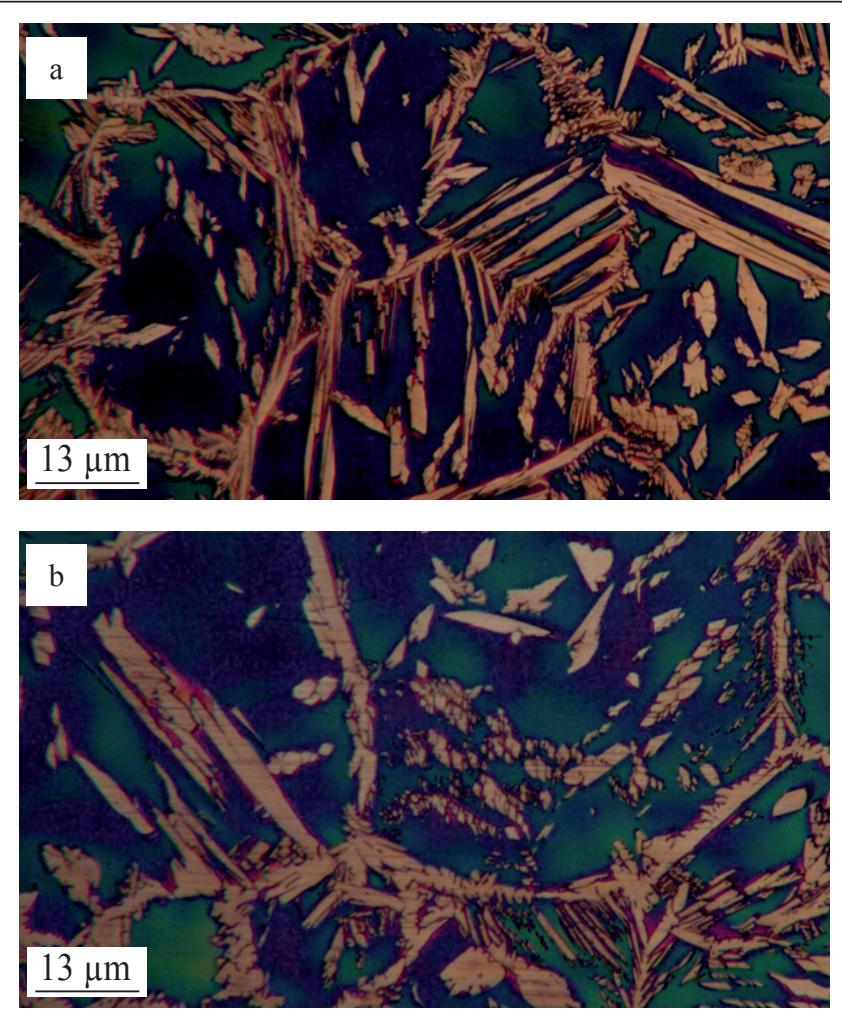

Figura 3. Micrografias da ZACTE das amostras soldadas com energias de 2,57 kJ/mm. Espessuras: (a) $10 \mathrm{~mm}$, (b) $20 \mathrm{~mm}$. Fase clara austenita e fase escura ferrita. Ataque BEHARA II.

Tabela 6. Quantificação das fases na zona afetada pelo calor de temperatura elevada.

\begin{tabular}{|c|c|c|c|}
\hline $\begin{array}{c}\text { Energia } \\
(\mathbf{k J} / \mathbf{m m})\end{array}$ & $\begin{array}{c}\text { Espessura } \\
(\mathbf{m m})\end{array}$ & $\begin{array}{c}\text { Fração de ferrita } \\
\mathbf{( \% )}\end{array}$ & $\begin{array}{c}\text { Fração de austenita } \\
\mathbf{( \% )}\end{array}$ \\
\hline 0,66 & 10 & 64 & 36 \\
\hline 0,66 & 20 & 65 & 35 \\
\hline 2,57 & 10 & 68 & 32 \\
\hline 2,57 & 20 & 70 & 30 \\
\hline
\end{tabular}


soldadas apresentaram os mesmos difratogramas. Nas Figuras 4 e 5 são mostrados os resultados das difrações das amostras de maiores e menores energias. Podemos observar que existem apenas ferrita e austenita nas amostras soldadas.

A análise por Microscopia Eletrônica de Varredura foi feita em todas as amostras soldadas como complemento aos resultados da difração de raios-X em respeito à precipitação da fase sigma. Mais uma vez não foi encontrado nenhum indício de precipitação desta fase em nenhuma das condições de soldagem avaliada. Nas Figuras 6 e 7 são apresentadas as imagens da ZACTE obtidas via MEV para as amostras soldadas com a maior e menor energia de soldagem.

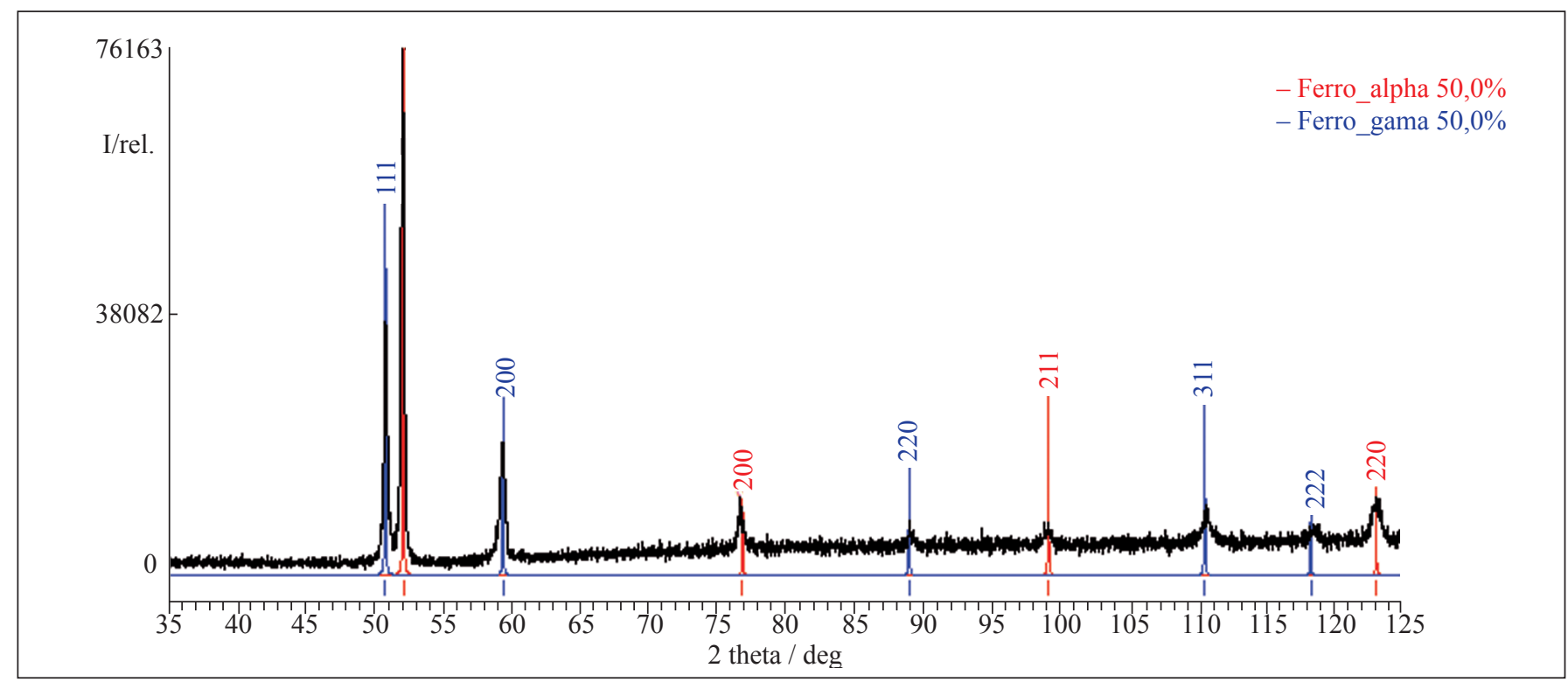

Figura 4. Difração de raios x para a amostra de $10 \mathrm{~mm}$ soldada com energia de $0,66 \mathrm{~kJ} / \mathrm{mm}$.

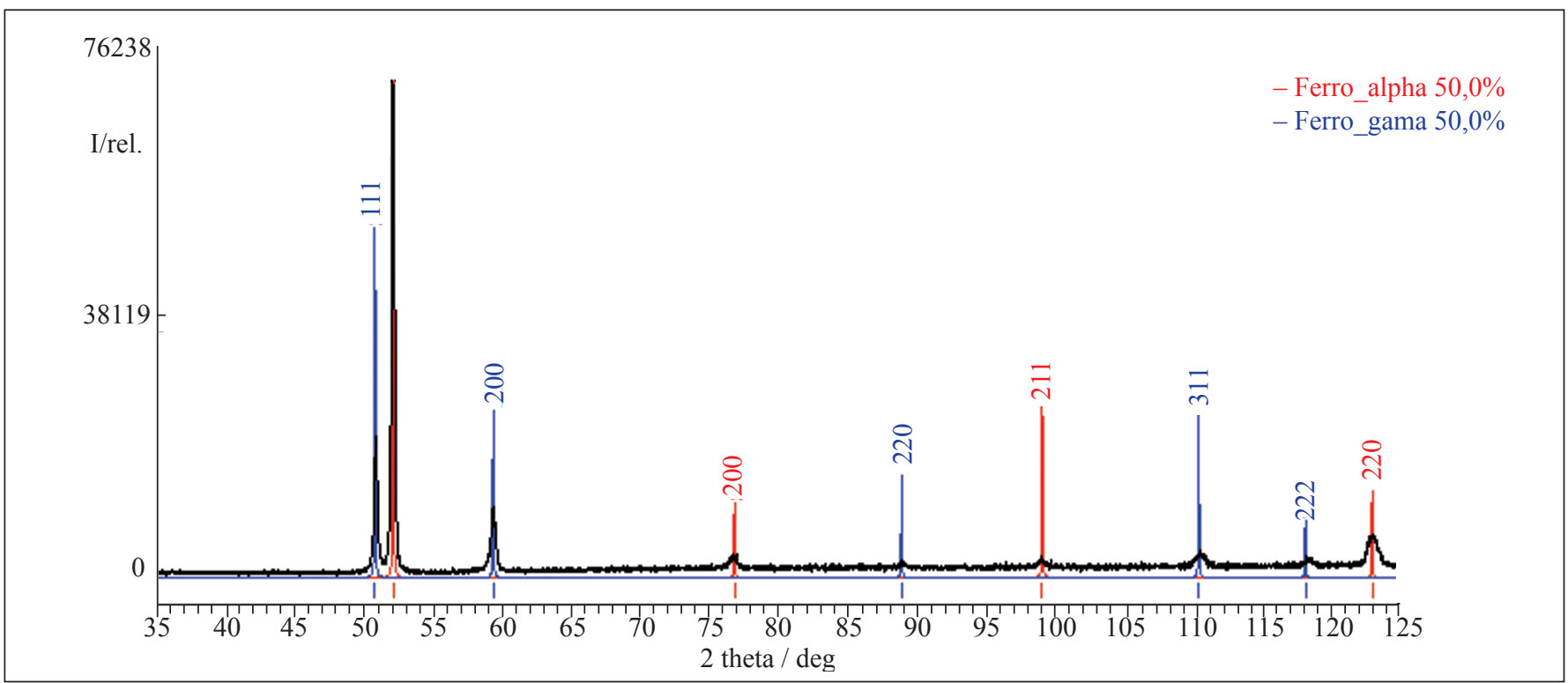

Figura 5. Difração de raios x para a amostra de $10 \mathrm{~mm}$ soldada com energia de 2,57 kJ/mm.

\section{Conclusão}

Não foi constatada a presença de fase sigma na faixa de energia de soldagem investigada neste trabalho e nas duas espessuras utilizadas do aço inoxidável duplex 2205, o que foi confirmado através de três técnicas de caracterização, ou seja, microscopia óptica, microscopia eletrônica de varredura e difração de raios-X. Nas condições 

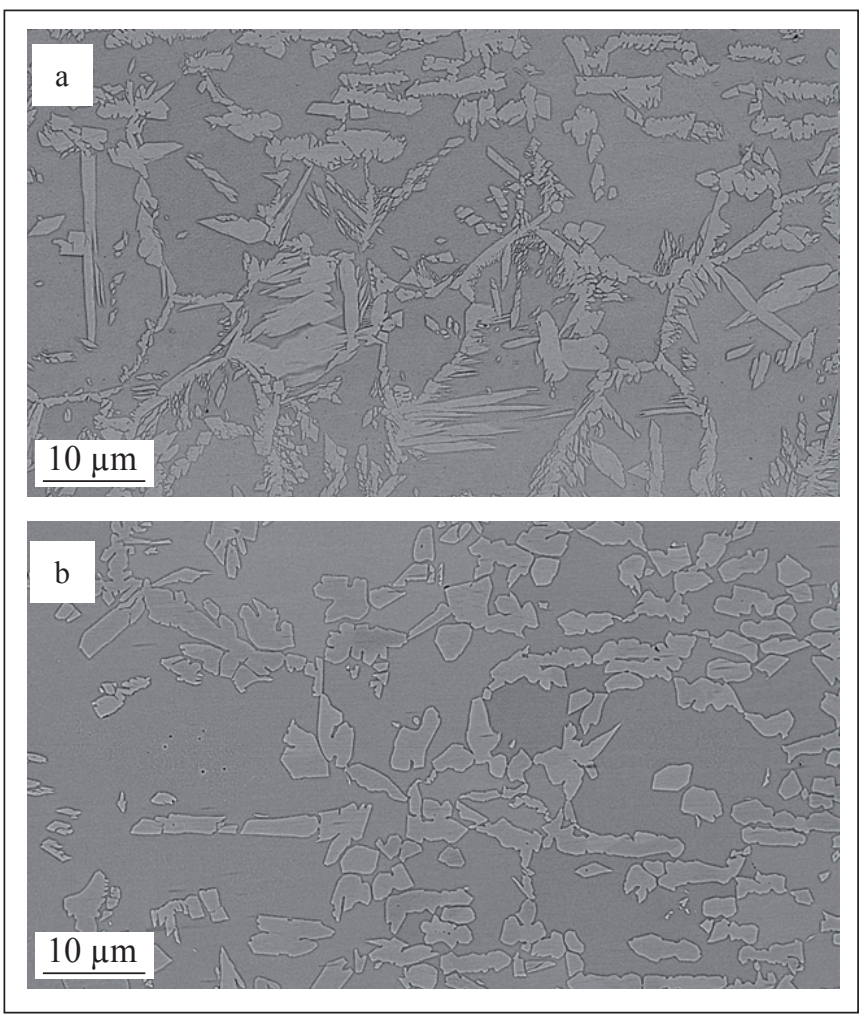

Figura 6. Microestrutura da ZACTE do AID de espessura $10 \mathrm{~mm}$ soldado com energia de soldagem de: (a) $0,66 \mathrm{~kJ} / \mathrm{mm}$ e (b) $2,57 \mathrm{~kJ} / \mathrm{mm}$.
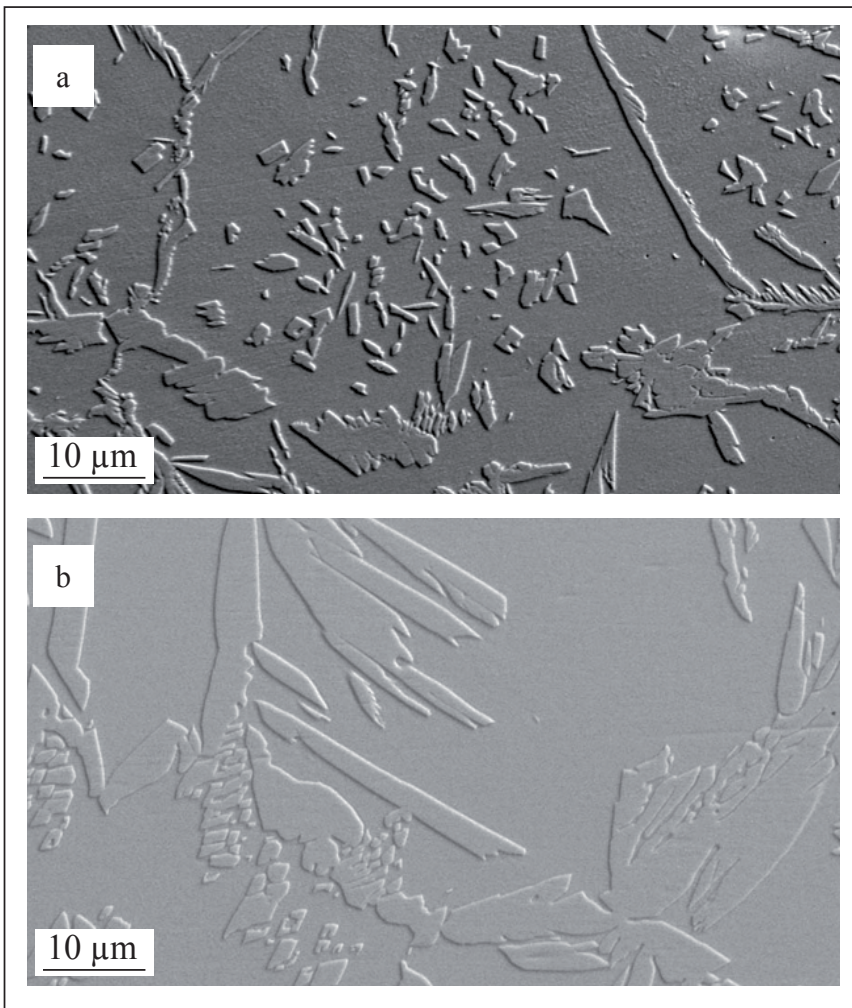

Figura 7. Microestrutura da ZACTE do AID de espessura $20 \mathrm{~mm}$ soldado com energia de soldagem de: (a) $0,66 \mathrm{~kJ} / \mathrm{mm}$ e (b) $2,57 \mathrm{~kJ} / \mathrm{mm}$. avaliadas neste trabalho, a fração volumétrica de ferrita presente na ZACTE apresentou um ligeiro aumento com o aumento da energia de soldagem, mas permaneceu praticamente inalterada quando a comparação foi feita utilizando diferentes espessuras de metal base para uma mesma energia de soldagem. Além disto, o trabalho mostrou que as três técnicas de caracterização (microscopia óptica x microscopia eletrônica de varredura x difração de raios-X) podem ser utilizadas de forma a se complementarem, sendo importantes e eficazes ferramentas na avaliação microestrutural de aços inoxidáveis duplex após soldagem, permitindo a identificação dos constituintes presentes bem como na determinação das suas frações volumétricas.

\section{Agradecimentos}

Ao CNPq e FAPERJ. Às empresas Aperam South America, ESAB e White Martins pelo fornecimento dos recursos materiais para estudo e pela presteza em fornecer as informações necessárias sempre que requisitadas.

\section{Referências}

1. Ramirez Londoño, A.J., Estudo da precipitação de nitreto de cromo e fase sigma por simulação térmica da zona afetada pelo calor na soldagem multipasse de aços inoxidáveis duplex. Dissertação de Mestrado (1997). Escola Politécnica/USP, São Paulo (SP).

2. Solomon, HD.; Devine, T.M. A tale of two phases, In: Conference Duplex Stainless Steels'82, St. Louis-ESA, Ohio, USA, 1983, p. 693-756.

3. Maehara, Y.; Koike, M.; Fujino, N.; Kunitake, T. Precipitation of fase s in $25 \mathrm{Cr}-7 \mathrm{Ni}-3 \mathrm{Mo}$ duplex phase stainless steel. Transactions ISIJ. V. 23 (1983), p. 240-246.

4. Gunn, R.N., Duplex Stainless Steels: Microstructures, Properties and Applications. Cambridge: Abington Publishing, 1997, p. 204.

5. Liljas, M. The welding metallurgy of duplex stainless steels. In: Conference Duplex Stainless Steels'94, GlasgowScotland, Escócia, 1994, Proceedings.: TWI, paper KV.

6. Varol, I. Microstructure/Property Relationships in the Weld Heat Affected Zone of Duplex stainless steels. Dissertation (Doctorate) (1992). Department of Welding Engineering, The Ohio State University. Columbus-Ohio.

7. Modenesi, P. J.; Marques, P. V.; Santos, D. B.; Introdução à Metalurgia da Soldagem. Departamento de Engenharia Metalúrgica e de Materiais, Universidade Federal de Minas Gerais, (2006). Belo Horizonte - MG. 